\title{
Prevalence and awareness of osteopenia in perimenopausal women in Navi Mumbai, Maharashtra, India
}

\author{
Ajay Dodeja ${ }^{1 *}$, Anushka Makhija1, Ashita Rane', Meeta Dodeja ${ }^{2}$
}

\begin{abstract}
${ }^{1}$ Department of Physiology, MGM Medical College and Hospital, Navi Mumbai, Maharashtra, India
${ }^{2}$ Department of Obstetrics and Gynecology, Jupiter Hospital, Thane, Maharashtra, India
\end{abstract}

Received: 20 November 2018

Accepted: 29 December 2018

\author{
*Correspondence: \\ Dr. Ajay Dodeja, \\ E-mail: ajaydodeja1995@gmail.com
}

Copyright: (C) the author(s), publisher and licensee Medip Academy. This is an open-access article distributed under the terms of the Creative Commons Attribution Non-Commercial License, which permits unrestricted non-commercial use, distribution, and reproduction in any medium, provided the original work is properly cited.

\begin{abstract}
Background: Osteopenia is considered as precursor of osteoporosis. Osteoporosis is a major public health problem associated with substantial morbidity and socio-economic burden worldwide. Osteopenia occurs more frequently in most menopausal women. Early detection of the same can be beneficial to control prevalence of osteoporosis and also to reduce the fracture rates.

Methods: A cross-sectional quantitative study using DEXA (Dual Energy X-ray Absorptiometry) was conducted on 80 women. A self-structured questionnaire was used to evaluate the level of awareness among the study subjects. The data was analyzed using statistical tests such as Chi-Square test for association. The level of significance was set at $5 \%$.

Results: The prevalence of osteopenia in the studied population was $63.75 \%$. The mean age was recorded to be 40.35 years. The mean age of women with menopause in this study is 50.62 years. Out of the 51(63.75\%) women diagnosed with osteopenia, $5.9 \%$ were underweight, $33.3 \%$ were normal and $49 \%$ were obese. Of the diseased, $37.3 \%$ experienced adequate amount sunlight exposure required while $62.7 \%$ did not. Out of the 80 women interviewed $43.75 \%$ were aware about osteopenia, its causes and complications; which $56.25 \%$ were unaware about the same.

Conclusions: Women were screened for osteopenia with the help of DEXA scan according to the (World Health Organization) WHO, T-Score criteria-which may go undiagnosed otherwise and may experience the risk and complications of osteoporosis.
\end{abstract}

Keywords: Awareness, BMD (Bone Mineral Density), DEXA, Menopause, Osteopenia, Osteoporosis, Sunlight

\section{INTRODUCTION}

Osteopenia is a medical condition in which the protein and mineral content of bone tissue is reduced, leading to compromised skeletal strength and increased susceptibility to fractures; but less severely than in osteoporosis. Osteoporosis is characterized by reduced bone strength that is more common in postmenopausal women. ${ }^{1}$ Osteopenia has been studied comprehensively, because of its association with osteoporosis and its high prevalence in India. Low bone mass and bone quality both play an important role in osteoporosis. The former can be easily measured and hence has become the diagnostic tool for osteoporosis. ${ }^{2}$ Osteopenia is a forerunner to osteoporosis. The latter is one of the most common adverse effects of menopause with increased occurrence of morbidity and mortality. The world health organization declared osteoporosis as one of the four main enemy of mankind along with cancer, heart attack and stroke. ${ }^{3}$ Bones are constantly remodelled with old bone being replaced by new bone. The renewing rate is estimated at $20 \%$ in children and about $3 \%$ to $5 \%$ in 
adults. ${ }^{4}$ There is constant decrease of bone mass both in men and women. However, women face rapid bone loss after age of 50 due to decline in oestrogen level during menopause. The risk of mortality from osteoporosis is equal to the risk of mortality from breast cancer and about four times greater than the risk of uterine cancer. ${ }^{5}$ Osteoporosis is a silent disease, reflected only in a low bone density, until a fracture occurs. Similar to asymptomatic conditions such as hypertension and dyslipidaemia predispose to stroke and myocardial infarction respectively, low bone density predisposes to osteoporotic fractures. $30 \%-50 \%$ of women and $15 \%$ $30 \%$ of men suffer from osteoporosis-related fractures in their lifetime. ${ }^{6}$ With increasing longevity of Indian population, osteoporotic fractures are a major cause of morbidity and mortality in the elderly. Hence, it is crucial to identify these women at risk of developing osteopenia. Bone status can be evaluated by bone mineral density (BMD) measurements with the help of DEXA scan, as it is one of the important tools in diagnosis of osteopenia. Hence, preventive and therapeutic measures can be initiated at the earliest.

\section{METHODS}

The present cross-sectional quantitative study was carried out at a tertiary care hospital in Navi Mumbai; over a time period of one week in June 2014. The study was initiated after obtaining ethical clearance from the Institutional Ethics Review Committee (IERC).

\section{Inclusion criteria}

- The study subjects were 80 healthy women belonging to the age group of 30 to 60 years.

\section{Exclusion criteria}

- Subjects who were pregnant or had chronic diseases like diabetes, hypertension, etc. were excluded.

Subjects were included irrespective of their gravida and marital statuses'. Informed written consent was taken from all the subjects who participated. Prevalence of osteopenia was evaluated with the help of DEXA scan. According to World Health Organization (WHO); Tscore of-1.1 or greater indicates normal bone BMD, Tscore between-1.0 and-2.5 indicates low BMD suggesting osteopenia and a T-score lower than-2.5 indicates very low BMD suggestive of osteoporosis. A self-structured questionnaire was used to analyze awareness of these women about osteopenia. The questionnaire was used to obtain information about socio-demographic, obstetric, menstrual and medical history. It also assessed subjects' lifestyle pattern and their knowledge about osteopeniarisk factors, causes, and complications. Height and weight of these women were recorded with the help of non-stretchable meter tape and an analogue weighing scale respectively, to evaluate their body mass index
(BMI). BMI was calculated as the weight divided by the square of height $\left(\mathrm{kg} / \mathrm{m}^{2}\right)$.

Classification of data to obtain correlation between BMI and prevalence of osteopenia was done according to the consensus statement: ${ }^{7}$

- Normal:18.0-22.9kg/m²

- Overweight: $23.0-24.9 \mathrm{~kg} / \mathrm{m}^{2}$

- Obesity: $>25 \mathrm{~kg} / \mathrm{m}^{2}$.

Since it was a cross-sectional study the subjects were grouped after statistical analysis of the data.

\section{Statistical analysis}

The data was analyzed using SPSS 20.0 and MS-Excel. Statistical test such as chi-square test, odds ratio was used for association. Level of significance was set at 5\% and that of higher significance at $1 \%$. All p-values less than 0.05 have been treated as significant values and less than 0.01 as highly significant values.

\section{RESULTS}

Of the 80 women interviewed 51 women were found to have osteopenia and 29 of them were normal. The mean age of women who had attained menopause was recorded to be 50.62 years. The mean T-score was evaluated to be -1.1. While osteopenia is defined by W.H.O as T-score between -1.0 and -2.5 . The mean age of women who were a part of the study group for the study was 40.35 years $(\mathrm{SD}=8.78)$ and their mean $\mathrm{BMI}$ was $24.21 \mathrm{~kg} / \mathrm{m}^{2}$ $(\mathrm{SD}=4.82)$ (Table 1).

Table 1: Mean and standard deviation.

\begin{tabular}{|l|l|l|}
\hline Parameters & Mean & Standard deviation (SD) \\
\hline Age (years) & 40.35 & 8.78 \\
\hline Weight $(\mathrm{kg})$ & 59.83 & 9.70 \\
\hline Height $(\mathrm{m})$ & 1.58 & 0.10 \\
\hline BMI $\left(\mathrm{kg} / \mathrm{m}^{2}\right)$ & 24.21 & 4.82 \\
\hline
\end{tabular}

$43.75 \%$ women who took part in the study were aware about osteopenia, its causes and complications; while $56.25 \%$ were unaware about the same. Out of the 51 women who had osteopenia $49.0 \%$ were obese and $55.2 \%$ of the women who had normal BMD had normal BMI (Table 2). Among the women experiencing osteopenia, $62.7 \%$ did not obtain sufficient amount of sunlight exposure, while $75.9 \%$ of the normal women got adequate sunlight exposure. Majority $(69 \%)$ of the women with normal BMD experienced sunlight exposure for about two hours every day. However, $20.7 \%$ normal women reported to have no sunlight exposure in their routine lifestyle, which suggests that exposure to sunlight may not be the only factor affecting the incidence of osteopenia. In present study, the groups of normal women who exercised 3-5 days every week and who rarely exercised were found to be equal. 
Table 2: Prevalence trends.

\begin{tabular}{|c|c|c|c|c|c|c|}
\hline Parameters & & Osteopenia & Normal & Chi-square & df & p-value \\
\hline \multirow{3}{*}{ Education } & Up to $10^{\text {th }}$ standard & $31.4 \%$ & $6.9 \%$ & \multirow{3}{*}{11.004} & \multirow{3}{*}{2} & \multirow{3}{*}{$0.004 * *$} \\
\hline & Up to graduation & $49.0 \%$ & $86.2 \%$ & & & \\
\hline & Post-graduation and higher & $19.6 \%$ & $6.9 \%$ & & & \\
\hline \multirow{4}{*}{ BMI } & Underweight & $5.9 \%$ & $3.4 \%$ & \multirow{4}{*}{9.077} & \multirow{4}{*}{3} & \multirow{4}{*}{$0.028^{*}$} \\
\hline & Normal & $33.3 \%$ & $55.2 \%$ & & & \\
\hline & Overweight & $11.8 \%$ & $24.1 \%$ & & & \\
\hline & Obese & $49.0 \%$ & $17.2 \%$ & & & \\
\hline \multirow{2}{*}{$\begin{array}{l}\text { Exposure to } \\
\text { sunlight }\end{array}$} & Yes & $37.3 \%$ & $75.9 \%$ & \multirow{2}{*}{11.029} & \multirow{2}{*}{1} & \multirow{2}{*}{0.001 ** } \\
\hline & No & $62.7 \%$ & $24.1 \%$ & & & \\
\hline \multirow{4}{*}{$\begin{array}{l}\text { Hours of } \\
\text { exposure }\end{array}$} & $<1$ hour & $25.5 \%$ & $37.9 \%$ & \multirow{4}{*}{16.126} & \multirow{4}{*}{3} & \multirow{4}{*}{$0.001 * *$} \\
\hline & 1-2 hours & $11.8 \%$ & $31.1 \%$ & & & \\
\hline & 2-4 hours & $0.0 \%$ & $6.9 \%$ & & & \\
\hline & No exposure & $62.7 \%$ & $24.1 \%$ & & & \\
\hline \multirow{4}{*}{ Exercise } & Everyday & $35.3 \%$ & $13.8 \%$ & \multirow{4}{*}{7.572} & \multirow{4}{*}{3} & \multirow{4}{*}{0.056} \\
\hline & 3-5 days/ week & $15.7 \%$ & $37.9 \%$ & & & \\
\hline & Once a week & $5.9 \%$ & $10.4 \%$ & & & \\
\hline & Rarely & $43.1 \%$ & $37.9 \%$ & & & \\
\hline
\end{tabular}

* Significant value since $\mathrm{p}$-value $<0.05$, ** highly significant value since $\mathrm{p}$-value $<0.01$

Table 3: Awareness.

\begin{tabular}{|c|c|c|c|c|c|c|}
\hline Parameters & & Aware & Unaware & Chi-Square & Df & p-value \\
\hline \multirow{3}{*}{ Education } & Up to $10^{\text {th }}$ standard & $2.9 \%$ & $37.8 \%$ & \multirow{3}{*}{13.842} & \multirow{3}{*}{2} & \multirow{3}{*}{$0.001 * *$} \\
\hline & Up to graduation & $77.1 \%$ & $51.1 \%$ & & & \\
\hline & Post-graduation and higher & $20.0 \%$ & $11.1 \%$ & & & \\
\hline \multirow{5}{*}{$\begin{array}{l}\text { Frequency of health } \\
\text { checks }\end{array}$} & None & $0.0 \%$ & $97.8 \%$ & \multirow{5}{*}{76.249} & \multirow{5}{*}{4} & \multirow{5}{*}{$0.000 * *$} \\
\hline & Quarterly & $2.9 \%$ & $0.0 \%$ & & & \\
\hline & Half yearly & $17.1 \%$ & $0.0 \%$ & & & \\
\hline & Annually & $45.7 \%$ & $0.0 \%$ & & & \\
\hline & When required & $34.3 \%$ & $2.2 \%$ & & & \\
\hline \multirow{2}{*}{ Prevalence of osteopenia } & Osteopenia & $48.6 \%$ & $75.6 \%$ & \multirow{2}{*}{6.023} & \multirow{2}{*}{1} & \multirow{2}{*}{$0.013^{*}$} \\
\hline & Normal & $51.4 \%$ & $24.4 \%$ & & & \\
\hline
\end{tabular}

* Significant value since $\mathrm{p}$-value $<0.05, * *$ highly significant value since $\mathrm{p}$-value $<0.01$

Among the group women who had lower BMD $43.1 \%$ of them reported that they rarely exercised. Regardless of the results there was no statistically significant association established between prevalence of osteopenia and the amount of time these women allocated to exercise in their routine lifestyle (Table 3).

Higher the level of education, lower is the difference between amount of aware and unaware women in a particular education group (Figure 1).

Most $(75.6 \%)$ of the women who were unaware about osteopenia had the disease on the contrary more than half $(51.4 \%)$ of the women who were aware about the osteopenia, it's treatment and precaution had normal bone mineral density. $97.8 \%$ of the women who were unaware about osteopenia experienced a health check for the first time during the present study. The level of awareness was seen to be increasing as among the groups of women who underwent health checks more frequently.

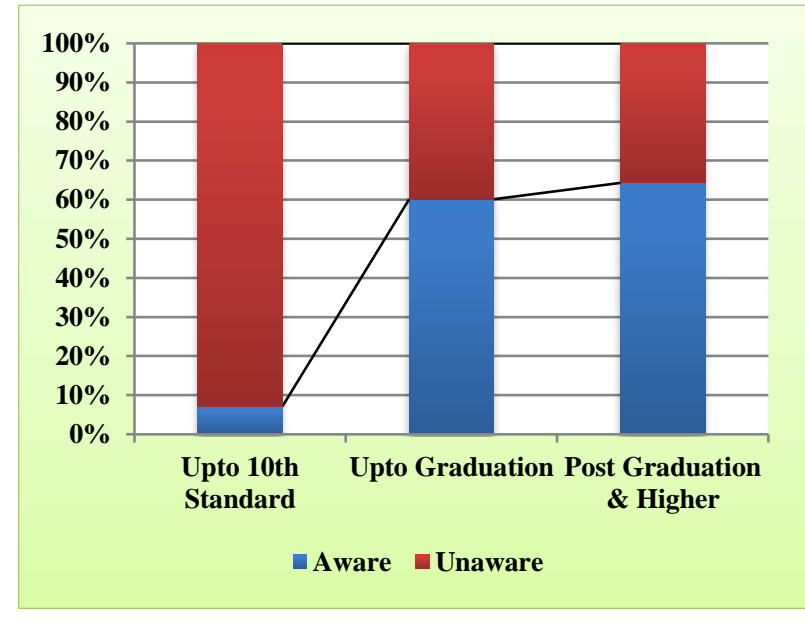

Figure 1: Trend in awareness-based on education.

The peak incidence of osteopenia was found in the age group of 50-60 years (Figure 2). 


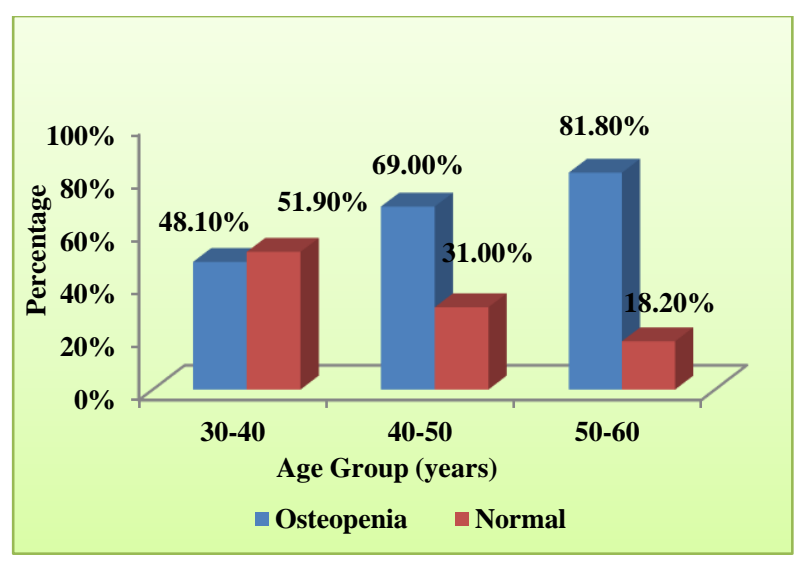

Figure 2: Prevalence of osteopenia across age.

\section{DISCUSSION}

Peak bone mass is generally obtained by 30 years of age. From mid-thirties there is a gradual and continuous bone loss that accelerates during perimenopause in women. Peak bone mass is primarily determined by genes but may be modified to a considerable extent by certain factors like physical activity, calcium, vitamin D nutrition, smoking, alcohol, concurrent illnesses and medications (glucocorticoids, antiepileptics). ${ }^{8}$ Normal bone loss averages $0.7 \%$ per year. It gets accelerated at the time of menopause to $2-5 \%$ per year, which may continue for 10 years. ${ }^{9}$ As the age advances, the incidence of osteopenia and osteoporosis, the silent diseases increase. ${ }^{10}$ In present study it was observed that the bone density did decrease with increase in age (figure 1). The non-modifiable risk factors are female sex, old age, small thin built, Caucasians/Asians and family history of fractures. Important modifiable risk factors are vitamin D deficiency, sedentary lifestyle, smoking, excessive consumption of alcohol and caffeine intake.(9) Hypotheses regarding vitamin D deficiency in the urban Indian population include poor sunlight exposure, skin pigmentation, atmospheric pollution, and a vitamin $\mathrm{D}$ deficient $\operatorname{diet}^{9,11}$ Awumey et al, also reported altered vitamin D metabolism in cultured skin fibroblasts from Indians. ${ }^{12}$ The risk factors for vitamin D deficiency increase with time (aging and declining physical activity). ${ }^{13}$ Just like any other preventable disease, osteopenia can also be prevented by a good diet consisting of adequate amount of calcium and other minerals. Maintaining a calcium intake of at least 1000$1200 \mathrm{mg} /$ day has long been recommended for older individuals to treat and prevent osteoporosis. ${ }^{14}$ Many countries in Asia have average dietary calcium intake less than 500mg/day. Countries in Africa and South America mostly have low calcium intake between about 400 and $700 \mathrm{mg} /$ day. ${ }^{15}$ While (in Table 2) the study shows association between prevalence of osteopenia and modifiable risk factors. BMI is significantly associated. In another study carried out by Asomaning $\mathrm{K}$, et al women with low BMI are at increased risk of osteoporosis. The change in risk associated with a 1-unit change in BMI (approximately 5-8 lb.) is of greater magnitude than most other modifiable risk factors ${ }^{16}$.

In the study, exposure to sunlight and hours of exposure to sunlight show highly significant association with incidence of osteopenia (Table 2). High occurrence of modifiable risk factors could also be due to less awareness as shown in the study as $75.6 \%$ of the subjects were unaware and had osteopenia; and $51.4 \%$ of them were aware and did not have osteopenia. Women who were younger, better educated, who exercised regularly were more likely to have heard of osteoporosis. ${ }^{17}$. Highly significant association was observed between education and awareness.

In another study by Nirmal Raj Gopinathan et al, the results show that there is a great deficit in the awareness level of postmenopausal Indian women regarding osteoporosis. ${ }^{18}$ Most of the women were unaware of the condition and the means to prevent it. The study emphasizes that health care professionals have lot of ground to cover to decrease the incidence of osteoporosis and its associated health problem. ${ }^{18}$

Unfortunately, $97.8 \%$ of the women interviewed and found to be osteopenic, expressed that they never got health check-ups done before.

Frequency of health check-ups has been highly significant to awareness in present study (Table 3). Community based health education programs on osteopenia and life style modifications to prevent the same, which target expansive population irrespective of their socio-economic and educational status, could be implemented. Increasing the awareness of osteopenia and its risk factors will be a potent effort to bring about reduction in the prevalence of osteopenia, in India.

\section{Funding: No funding sources}

Conflict of interest: None declared

Ethical approval: The study was approved by the Institutional Ethics Committee

\section{REFERENCES}

1. Khadilkar AV, Mandlik RM. Epidemiology and treatment of osteoporosis in women: an Indian perspective. Int J Womens Health. 2015;19;7:841-50.

2. Bharathi R, Baby D. Preliminary screening of osteopenia and osteoporosis using quantitative ultrasound bone densitiometry. Indian J Appl Res. 2014;4(1):256-8.

3. Lim SY, Bolster MB. Current approaches to osteoporosis treatment. Curr Opin Rheumatol 2015;27(3):216-24.

4. Berendsen AD, Olsen BR. Bone development. Bone. 2015;80:14-8.

5. Berarducci A. Senior nursing students' knowledge of osteoporosis. Orthop Nurs. 2004;23(2):121-7. 
6. Randell A, Sambrook PN, Nguyen TV, Lapsley H, Jones G, Kelly PJ, et al. Direct clinical and welfare costs of osteoporotic fractures in elderly men and women. Osteopor Int. 1995;5(6):427-32.

7. Misra A, Chowbey P, Makkar BM, Vikram NK, Wasir JS, Chadha D, et al. Consensus statement for diagnosis of obesity, abdominal obesity and the metabolic syndrome for Asian Indians and recommendations for physical activity, medical and surgical management. J Ass Physic India. 2009;57(2):163-70.

8. Francis RM, Harrington F, Turner E, Papiha SS, Datta HK. Vitamin D receptor gene polymorphism in men and its effect on bone density and calcium absorption. Clin Endocrinol. 1997;46:83-6.

9. Hari Kumar K, Muthukrishnan J, Verma A, Modi K. Correlation between bone markers and bone mineral density in postmenopausal women with osteoporosis. Endoc Pract. 2008;14(9):1102-7.

10. Sharma S, Tandon VR, Mahajan A, Kour A, Kumar D. Preliminary screening of osteoporosis and osteopenia in urban women from Jammu using calcaneal QUS. Indian J Med Sci. 2006;60:183-9.

11. Arya V, Bhambri R, Godbole MM, Mithal A. Vitamin D status and its relationship with bone mineral density in healthy Asian Indians. Osteopor Int. 2004;15(1):56-61.

12. Awumey EM, Mitra DA, Hollis BW, Kumar R, Bell NH. Vitamin D metabolism is altered in Asian Indians in the southern United States: a clinical research center study. J Clinic Endocrinol Metabol. 1998;83(1):169-73.
13. Muscogiuri G. Vitamin D: past, present and future perspectives in the prevention of chronic diseases. Eur J Clin Nutr. 2018;72(9):1221-5.

14. Tai V, Leung W, Grey A, Reid IR, Bolland MJ. Calcium intake and bone mineral density: systematic review and meta-analysis. BMJ. 2015;351:h4183.

15. Balk EM, Adam GP, Langberg VN, Earley A, Clark P, Ebeling PR, et al. Global dietary calcium intake among adults: a systematic review. Osteoporosis Int. 2017;28(12):3315-24.

16. Asomaning K, Bertone-Johnson ER, Nasca PC, Hooven F, Pekow PS. The association between body mass index and osteoporosis in patients referred for a bone mineral density examination. J Womens Health (Larchmt). 2006;15(9):1028-3.

17. Saw SM, Hong CY, Lee J, Wong ML, Chan MF, Cheng A, et al. Awareness and health beliefs of women towards osteoporosis. Osteoporos Int. 2003;14(7):595-601.

18. Gopinathan NR, Sen RK, Behera P, Aggarwal S, Khandelwal N, Sen M. Awareness of osteoporosis in postmenopausal Indian women: An evaluation of Osteoporosis Health Belief Scale. J Midlife Health. 2016;7(4):180-4.

Cite this article as: Dodeja A, Makhija A, Rane A, Dodeja M. Prevalence and awareness of osteopenia in perimenopausal women in Navi Mumbai, Maharashtra, India. Int J Reprod Contracept Obstet Gynecol 2019;8:519-23. 